\title{
Acoustical Behaviour of Disaccharide (Sucrose) in Aqueous Alkali Metal Halides at Varying Temperatures
}

\author{
S.THIRUMARAN ${ }^{*}$, GENE GEORGE $^{1}$ and P.BAKKIYALAKSHMI ${ }^{2}$ \\ * Department of Physics (DDE), Annamalai University, Annamalai Nagar-608002, India \\ ${ }^{1,2}$ Department of Physics, T.B.M.L College, Poraiyar, Tamil Nadu, India \\ thirumaran64@gmail.com
}

Received 29 March 2013 / Accepted 30 April 2013

\begin{abstract}
Interionic interactions of ternary mixtures of sucrose in aqueous alkali metal halides namely, sodium chloride $(\mathrm{NaCl})$, potassium chloride $(\mathrm{KCl})$, potassium bromide $(\mathrm{KBr})$ and potassium iodide (KI) at $303.15,308.15$ and $313.15 \mathrm{~K}$ was studied in this paper. For this, binary solvent mixture (water+ metal halides) was prepared at two molalities $(\mathrm{m})$ (Say, at $0.0 \mathrm{~m}$ and $0.3 \mathrm{~m}$ ). The related and relevant parameters correlated to the present study such as adiabatic compressibility $(\beta)$, apparent molal compressibility $\left(\varphi_{\mathrm{K}}\right)$, apparent molal volume $\left(\varphi_{\mathrm{V}}\right)$, limiting apparent molal compressibility $\left(\varphi_{\mathrm{K}}^{0}\right)$, limiting apparent molal volume $\left(\varphi_{\mathrm{V}}^{0}\right)$ and their associated constants $\left(\mathrm{S}_{\mathrm{K}}, \mathrm{S}_{\mathrm{V}}\right)$, partial transfer volume $\left(\Delta \varphi_{\mathrm{V}}^{0}\right)$ from water to aqueous solution and viscosity $B$-coefficient of Jones-Dole equations were meticulously evaluated to interpret the results in terms of interionic interactions such as solute-solvent, solute-solute, ion-solvent, ion-ion etc,, existing in the solution.
\end{abstract}

Keywords: Adiabatic compressibility, Apparent molar compressibility, Limiting apparent molar volume, Viscosity-B coefficient

\section{Introduction}

Studies on interactions of non ionic with ionic ones in different solvents are significant for investigating their physicochemical behavior. The study of carbohydrates and saccharides has become a subject of increasing interest because of the multidimensional, physical, biomedical and industrially useful properties of these ompounds ${ }^{1,2}$. In addition to their importance in the food, pharmaceuticals and chemical industries, simple saccharides have received considerable attention for their ability to protect biological macromolecules ${ }^{3}$. Most of the biochemical processes occur in aqueous solutions. So, studies on thermodynamic properties of biological molecules in aqueous solutions are important. Studies involving density and ultrasonic velocity measurements are important for elucidation of ion-solvent, ion-ion and solute-solvent interactions in the mixed solvent systems. Polyhydroxy compounds are popular stabilizing agents ${ }^{4}$ for the native state of proteins and enzymes. Stabilizing of polyols and saccharides are related to the number of configuration of the 
hydroxyl groups ${ }^{5}$. In fact, there are extensive volumetric and thermodynamic property studies of saccharides in aqueous solutions ${ }^{6}$, but very few have been conducted in aqueous halide solutions ${ }^{7,8}$. Multi component liquid mixtures are of great practical importance in many industrial processes. They provide a wide choice of solutions with appropriate compositions and properties.

The aim of the present investigation is to study the molecular interionic interactions of sucrose in aqueous $\mathrm{NaCl}, \mathrm{KCl}, \mathrm{KBr}$ and $\mathrm{KI}$ at varying temperatures, say, at $303.15,308.15$ and $313.15 \mathrm{~K}$.

\section{Experimental}

The chemicals used in this present study were procured from the reputed companies with minimum assay of $99.9 \%$. Freshly prepared doubly distilled water (sp. conductivity $-10^{-6} \mathrm{ohm}^{-1}$ $\mathrm{cm}^{-1}$ ) was used for preparing a fixed binary solvent mixture of (water + metal halides) at varying molalities, (say at $0.0 \mathrm{~m}$ and $0.3 \mathrm{~m}$ ) at $303.15,308.15$ and $313.15 \mathrm{~K}$. Aqueous solutions were prepared and used on the day they were prepared. The required quantity of binary mixture [water + alkali metal halides] was prepared under different molalties $(\mathrm{m})$ (say at $0.0 \mathrm{~m}$ and $0.3 \mathrm{~m}$.) In the present study, the alkali metal halides such as sodium chloride $(\mathrm{NaCl})$, potassium chloride $(\mathrm{KCl})$, potassium bromide $(\mathrm{KBr})$ and potassium iodide $(\mathrm{KI})$ were taken. The required quantity of sucrose was added as a solute in the binary mixture under different molalities. The chemicals were weighed in an electronic digital balance (SHIMADZU AX200, Japan Make) with a least count of $0.0001 \mathrm{~g}$. The density was determined using a specific gravity bottle by relative measurement method with an accuracy of $\pm 0.01 \mathrm{kgm}^{-3}$. An Ostwald's viscometer of $10 \mathrm{~mL}$ capacity was used for the viscosity measurement. Efflux time was determined using a digital chronometer within $\pm 0.01 \mathrm{~s}$. An ultrasonic interferometer having the fixed frequency of $2 \mathrm{MHz}$ (Mittal Enterprises, New Delhi-Model: F-81) with an overall accuracy of $2 \mathrm{~ms}^{-1}$ has been used for velocity measurement. An electronically digital operated constant temperature bath (RAAGA Industries, Chennai) has been used to circulate water through the double walled measuring cell made up of steel containing the experimental solution at desired temperature, whose accuracy is maintained at $\pm 0.1 \mathrm{~K}$.

\section{Results and Discussion}

The observed experimental values of density $(\rho)$, viscosity $(\eta)$ and ultrasonic velocity $(U)$ of sucrose in aqueous alkali metal halides such as sodium chloride, potassium chloride, potassium bromide and potassium iodide at varying molalities, say (at $0.0 \mathrm{~m}$ and $0.3 \mathrm{~m}$ ) at a varying temperatures of $303.15,308.15$ and $313.15 \mathrm{~K}$ are given in Table 1 . The relevant parameters such as adiabatic compressibility $(\beta)$, apparent molal compressibility $\left(\varphi_{\mathrm{K}}\right)$, apparent molal volume $\left(\varphi_{\mathrm{V}}\right)$, limiting apparent molal compressibility $\left(\varphi_{\mathrm{K}}^{0}\right)$, limiting apparent molal volume $\left(\varphi_{\mathrm{V}}^{0}\right)$ and their associated constants $\left(\mathrm{S}_{\mathrm{K}}, \mathrm{S}_{\mathrm{V}}\right)$, partial transfer volume $\left(\Delta \varphi_{\mathrm{V}}^{0}\right)$ from water to aqueous solution and viscosity $B$-coefficient of Jones-Dole equations for the sucrose in aqueous alkali metal halides at 303.15, 308.15 and 313.15K are listed in Tables 2-4.

In the present study, the values of density, viscosity and ultrasonic velocity (Table 1) of mixture increases with increase of molal concentration of sucrose (solute) in all the four liquid systems studies and however it all decreases with the rise of temperature, except in ultrasonic velocity, where it exhibits an increasing trend in all the liquid systems. The increasing trend of ultrasonic velocity in the mixtures suggests a moderate strong nature in which the solutes (sucrose) tend to attract the solvent (aqueous alkali metal halides) molecules. 
Table 1. The values of disaccharide (Sucrose) in aqueous alkali metal halides at $303.15 \mathrm{~K}, 308.15 \mathrm{~K}$ and $313.15 \mathrm{~K}$ for density $(\rho)$, viscosity $(\eta)$ and velocity $(\mathrm{U})$

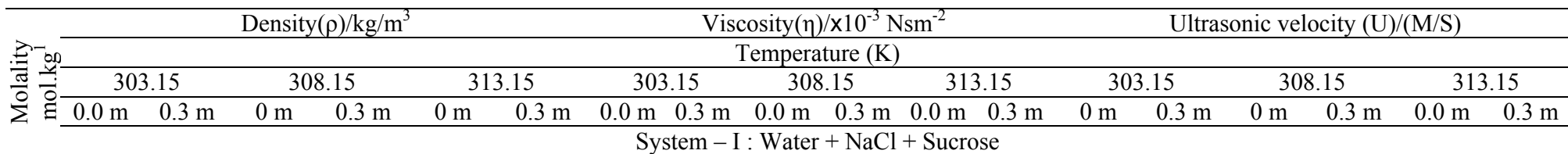

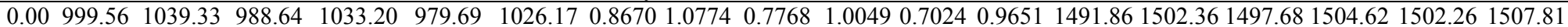

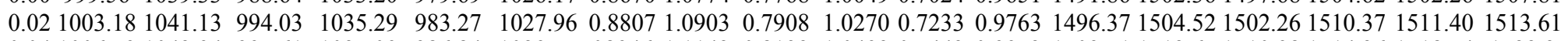

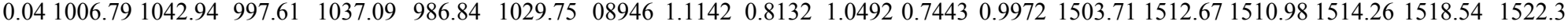

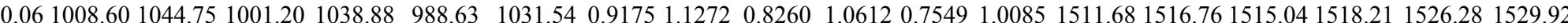

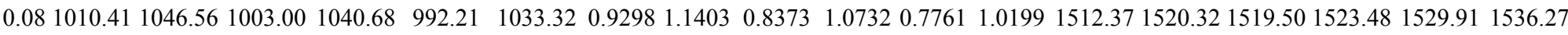

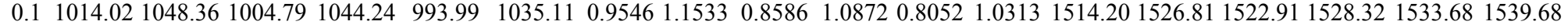
System - II : Water $+\mathrm{KCl}+$ Sucrose

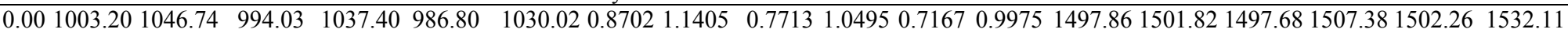

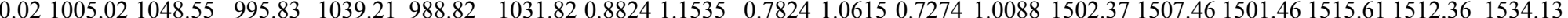

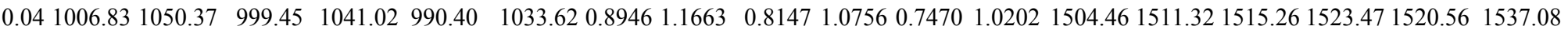

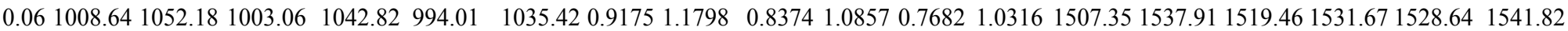

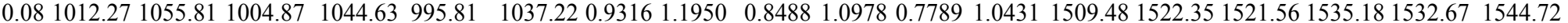

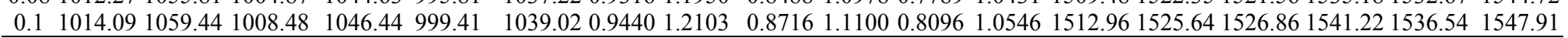
System -III : Water $+\mathrm{KBr}+$ Sucrose

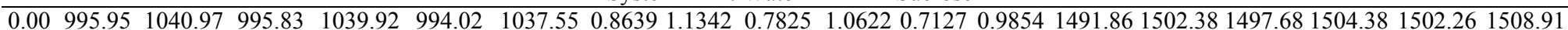

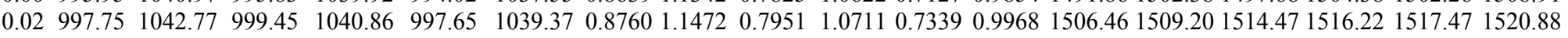

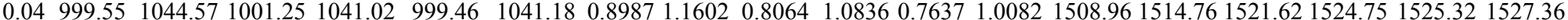

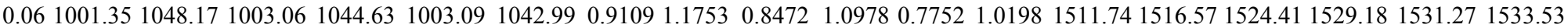

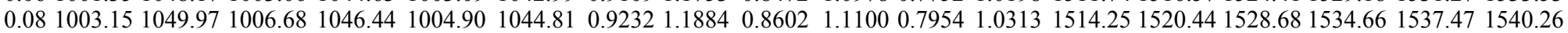
$\begin{array}{llllllllllllllllllllll}0.1 & 1006.75 & 1051.78 & 1010.29 & 1048.24 & 1008.53 & 1046.62 & 0.9478 & 1.2016 & 0.8831 & 1.1227 & 0.8076 & 1.0428 & 1516.42 & 1525.66 & 1530.37 & 1537.21 & 1541.28 & 1544.65\end{array}$ System - IV: Water + KI + Sucrose

$\begin{array}{llllllllllllllllllll}0.00 & 997.75 & 1044.66 & 995.83 & 1041.02 & 992.21 & 1039.28 & 0.8654 & 1.1271 & 0.7824 & 1.0429 & 0.7114 & 1.0064 & 1491.86 & 1503.86 & 1497.68 & 1509.28 & 1502.26 & 1510.86\end{array}$

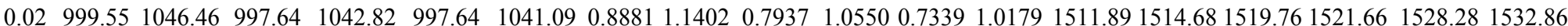

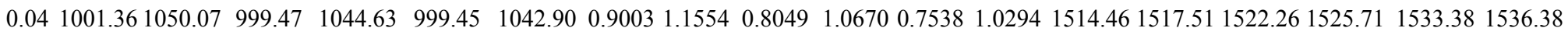
$\begin{array}{llllllllllllllllllllllll}0.06 & 1003.16 & 1051.88 & 1001.25 & 1045.56 & 1003.07 & 1044.71 & 0.9126 & 1.1683 & 0.8162 & 1.0778 & 0.7752 & 1.0409 & 1518.35 & 1522.42 & 1529.46 & 1532.80 & 1539.41 & 1542.88\end{array}$ $\begin{array}{lllllllllllllllllll}0.08 & 1004.97 & 1053.68 & 1004.87 & 1046.44 & 1006.69 & 1046.52 & 0.9248 & 1.1814 & 0.8369 & 1.0895 & 0.5968 & 1.0524 & 1521.77 & 1526.72 & 1531.78 & 1535.19 & 1544.54 & 1546.29\end{array}$

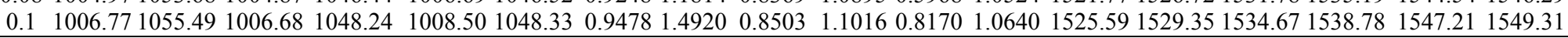


Table 2. The values of adiabatic compressibility $(\beta)$, apparent molal compressibility $\left(\Phi_{\mathrm{k}}\right)$ and apparent molal volume $\left(\Phi_{\mathrm{v}}\right)$ of sucrose in aqueous metal halides at $303.15,308.15$ and $313.15 \mathrm{~K}$

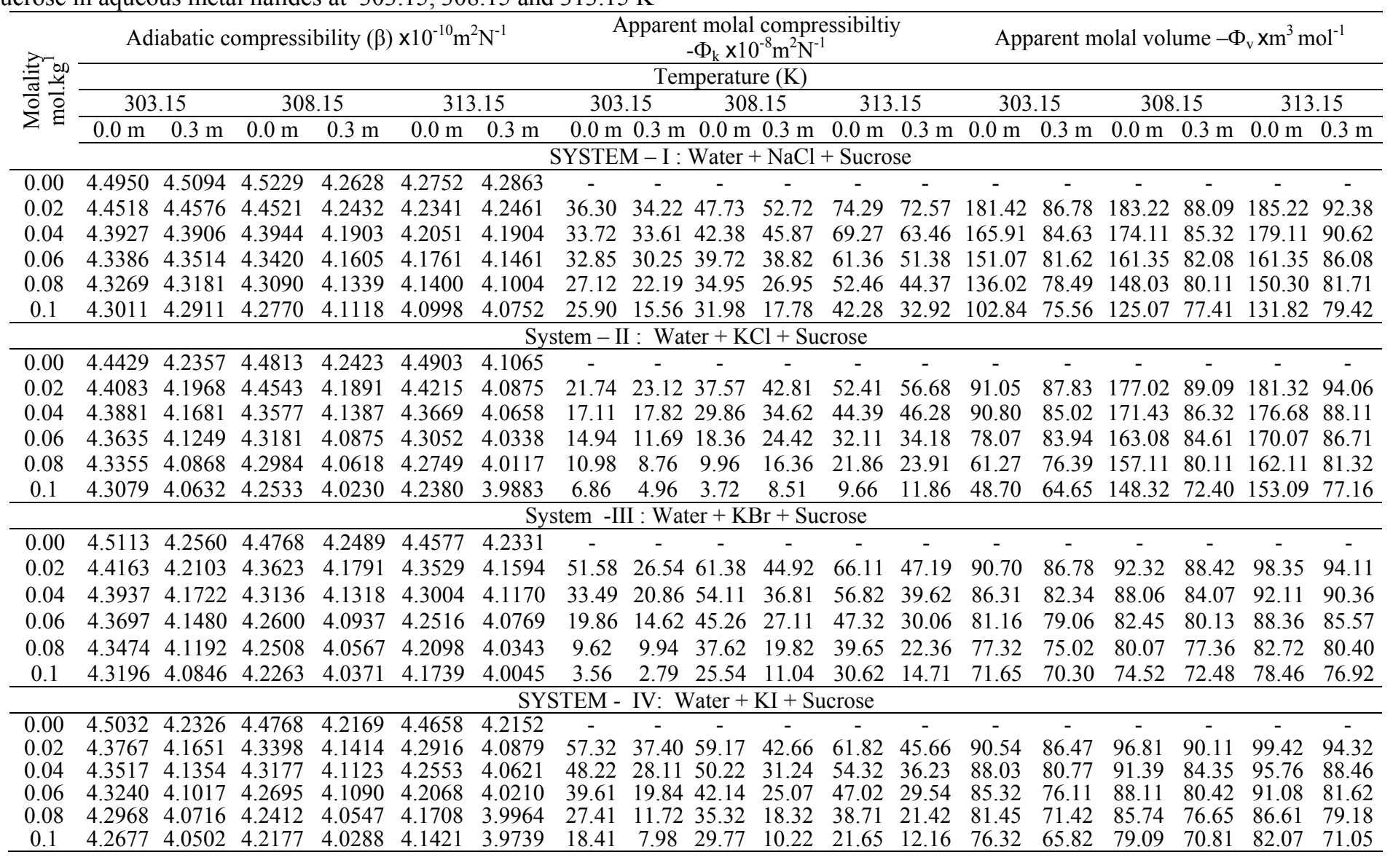


Table 3. The values of limiting apparent molal compressibility $\left(\phi \mathrm{k}^{0}\right)$ and limiting apparent molal volume $\left(\phi \mathrm{V}^{0}\right)$ their constant $\mathrm{S}_{\mathrm{k}}$ and $\mathrm{S}_{\mathrm{v}}$ of alkali metal halides in aqueous sucrose solution at $303.15,308.15$ and $313.15 \mathrm{~K}$

\begin{tabular}{|c|c|c|c|c|c|c|c|c|c|c|c|c|c|}
\hline \multirow{2}{*}{ 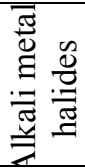 } & \multirow{2}{*}{ 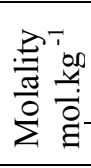 } & \multicolumn{3}{|c|}{$\begin{array}{c}\text { Limiting apparent molal } \\
\text { compressibility } \\
\left(\phi \mathrm{k}^{0}\right) \times 10^{-8} \mathrm{~m}^{2} \mathrm{~N}^{-1} \\
\end{array}$} & \multicolumn{3}{|c|}{$\mathrm{S}_{\mathrm{k}} \times 10^{-8} \mathrm{~N}^{-1} \mathrm{~m}^{1} \mathrm{~mol}^{-1}$} & \multicolumn{3}{|c|}{$\begin{array}{l}\text { Limiting apparent molal volume } \\
\qquad\left(\phi \mathrm{V}^{0}\right) \times \mathrm{m}^{3} \mathrm{~mol}^{-1}\end{array}$} & \multicolumn{3}{|c|}{$\mathrm{S}_{\mathrm{v}} \times 10^{-8} \mathrm{~N}^{-1} \mathrm{~m}^{1} \mathrm{~mol}^{-1}$} \\
\hline & & 303.15 & 308.15 & 313.15 & 303.15 & 308.15 & 313.15 & 303.15 & 308.15 & 313.15 & 303.15 & 308.15 & \\
\hline \multirow{2}{*}{$\mathrm{NaCl}$} & 0.0 & & & & & & & & & & 619.5486 & 652 & \\
\hline & 0.3 & & & & & & & & & & & & \\
\hline \multirow{2}{*}{$\mathrm{KCl}$} & 0.0 & -28.1179 & & & & & & & & & & & \\
\hline & 0.3 & -25.6584 & & -64.1789 & & & & & & & & & \\
\hline \multirow{2}{*}{$\mathrm{KBr}$} & 0.0 & -47.2456 & -89.56 & -129.4085 & 99.2538 & 188.16 & 236. & -162.8 & & & 342.1 & 7642 & \\
\hline & 0.3 & -29.9061 & & -61.9781 & 63.8192 & 177.39 & & & & -170.0 & $330.6^{\prime}$ & 338.2013 & \\
\hline \multirow{2}{*}{ KI } & 0.0 & -76.3831 & -86.6476 & -89.4067 & 160.4702 & 182.0347 & 187.8229 & -168.6631 & -176. & -182.0077 & 354.3319 & 370.7013 & 383.9216 \\
\hline & 0.3 & -42.2043 & -51.0096 & -28.0022 & 88.2752 & 107.1588 & 121.8576 & -152.2343 & -160.9005 & -165.7065 & 319.8254 & 338.1104 & 348.1269 \\
\hline
\end{tabular}

Table 4. The values of partial transfer volume, A - viscosity and $B$ - coefficient of Jones - Dole equation of sucrose in aqueous metal halides $303.15,308.15$ and $313.15 \mathrm{~K}$

\begin{tabular}{ccccccccccc}
\hline $\begin{array}{c}\text { Alkali metal } \\
\text { halides }\end{array}$ & $\begin{array}{c}\text { Molality } \\
\text { mol.kg }\end{array}$ & \multicolumn{3}{c}{ Partial transfer volume $\Delta \phi \mathrm{V}^{0}$} & \multicolumn{3}{c}{$\mathrm{A} \mathrm{dm}^{3 / 2} \mathrm{~mol}^{-1 / 2}$} & \multicolumn{3}{c}{$\mathrm{B} \mathrm{dm}^{3} \mathrm{~mol}^{-1}$} \\
\hline \multirow{2}{*}{$\mathrm{NaCl}$} & 0.0 & - & - & - & -0.0753 & -0.0233 & -0.0367 & 4.0384 & 1.1810 & 1.1284 \\
& 0.3 & 132.0642 & 135.8243 & 151.0495 & -0.7854 & -0.0949 & -0.0037 & 1.2215 & 0.7307 & 0.5287 \\
& 0.0 & - & - & - & -0.0626 & -0.1101 & -0.1483 & 1.7254 & 1.7190 & 1.0870 \\
$\mathrm{KCl}$ & 0.3 & 151.7038 & 161.7837 & 162.3674 & -0.0164 & -0.0039 & -0.0042 & 0.6555 & 0.4870 & 0.5649 \\
& 0.0 & - & - & - & -0.0470 & -0.1816 & -0.7183 & 1.1049 & 1.9099 & 1.1003 \\
$\mathrm{KBr}$ & 0.3 & 185.4547 & 198.8086 & 202.0039 & -0.0106 & -0.0427 & -0.0035 & 0.7147 & 0.6392 & 0.5947 \\
& 0.0 & - & - & - & -0.0918 & -0.0629 & -0.0099 & 4.5053 & 1.1058 & 0.5849 \\
$\mathrm{KI}$ & 0.3 & 202.0060 & 207.1665 & 218.2810 & -0.7618 & -0.0057 & -0.0028 & 1.4578 & 0.5822 & 0.5381 \\
\hline
\end{tabular}


Further, the increasing values of density with the increasing molal concentration of sucrose suggesting an enhanced molecular association in the solution. i.e., existence of molecular interaction between solute (sucrose) and solvent (aqueous alkali metal halides) molecules. The above causes may also be attributed for an increase in ultrasonic velocity in the mixtures. Such an increase in ultrasonic velocity in these solutions may be attributed to the cohesion brought about the ionic hydration. Incidentally, the density $(\rho)$ which is a measure of solute-solvent interactions. Increase of density with concentration indicates the increase in solute-solvent interactions, whereas the decrease in density indicates the lesser magnitude of solute-solvent interactions. Increase in density with concentration is due to the shrinkage in the volume which in turn is due to the presence of solute molecules. In other words, an increase in density may be interpreted to the structure-maker in the solution due to the added solute and the decrease in density with concentration indicates structure-breaker trend ${ }^{9}$.

Sucrose is formed by the elimination of a molecule of water from the combination of glysidic hydroxyl groups of $\alpha-D$-glucose. The fructose possess the furonose ring structure in the sucrose molecules, the pyranose ring is the dominant and more stable form in the free ketohexose. For sucrose formation both the carbonyl groups of individual units are involved in the formation of glycosidic bond. Sucrose contains no active group or so it does not exist mutarotation. This is a non-reducing sugar. Free Carbonyl is the active group of lactose and hemiacetyl is an active group of maltose $\mathrm{e}^{10}$.

From the Table 2, it is found that the values adiabatic compressibility ( $\beta$ ) seem decreases with increasing molality of sucrose in aqueous alkali metal halides as well as rise of temperature. The increasing electrostrictive compression of water around the molecules may result in decrease in the compressibility of the solution. The decrease in compressibility is attributed to the influence of the electrostatic field of ions $\left(\mathrm{Na}^{+}, \mathrm{Cl}^{-}, \mathrm{Br}^{-}, \mathrm{I}^{-}\right.$etc., $)$on the surrounding solvent molecules. The compressibility appears to be decreasing with decrease in hydrogen bond strength formed by solute and solvent molecules, in which the structural arrangement in the neighborhood of consistent solutes is considerably affected ${ }^{11}$.

The following observations are noticed from Table 2 on apparent molal compressibility $\left(\varphi_{\mathrm{K}}\right)$ and apparent molal volume $\left(\varphi_{\mathrm{V}}\right)$ of sucrose in aqueous alkali metal halides such as sodium chloride, potassium chloride, potassium bromide and potassium iodide at 303.15 , 308.15 and $313.15 \mathrm{~K}$.

The values of the $\left(\varphi_{\mathrm{K}}\right)$ and $\left(\varphi_{\mathrm{V}}\right)$ are all negative over the entire molality range of sucrose. It is interesting to note that,

i The values of apparent molal compressibility $\left(\varphi_{K}\right)$ are found to be increased with increasing molality $(\mathrm{m})$ of solute (sucrose).

ii It is interesting to note that the values of apparent molal volume $\left(\varphi_{\mathrm{V}}\right)$ exhibits the same trend as that of the apparent molal compressibility $\left(\varphi_{\mathrm{K}}\right)$

iii The larger values of apparent molal volume $\left(\varphi_{\mathrm{V}}\right)$ are found in System-IV, indicating that molecular association is more pronounced in that system.

All the above observations clearly suggest that the solute-solvent interaction takes place in all the liquid systems. The negative values of apparent molal compressibility indicates the hydrophilic interactions occurring in these systems. Since, more number of water molecules is available at lower concentration of metal halides, the chances for the penetration of solute molecules in the solvent molecules are highly favoured ${ }^{12}$. The increasing values of apparent molal compressibility and molal volume with increasing of solute content in aqueous medium reveal the strengthening of the solute-solvent interaction and the decreasing values 
of both parameters with rise of temperature clearly indicates that the solute-solvent interactions get weakened with addition of solutes. The evaluated parameter limiting apparent molal compressibility $\left(\varphi_{\mathrm{k}}{ }^{0}\right)$ which provide information's regarding the ion-solvent interactions and its related constant $\left(\mathrm{S}_{\mathrm{K}}\right)$ of the ion-ion interactions in the solution, which are systematically tabulated in Table 3 . It is noticed that the $\varphi_{\mathrm{K}}{ }^{0}$ values are negative in all the systems and decrease with increase of temperature, except in System-IV, where a non-linear trend is observed. Appreciable negative values of $\varphi_{\mathrm{K}}{ }^{0}$ for all the systems which suggest that the existence of ion-solvent interactions. Larger values of $\varphi_{\mathrm{K}}{ }^{0}$ are found in System-IV than other systems. Its related constant $\left(\mathrm{S}_{\mathrm{K}}\right)$ whose values are positive and they increase with elevation of temperature. Such a possession of positive values of $S_{K}$ indicate the strengthening of ion-ion interactions prevailing in the solution.

The perusal of Table 3 represents the values of limiting apparent molal volume $\varphi_{\mathrm{V}}{ }^{0}$ exhibiting negative values in all the four liquid systems and the same decrease with increase of temperature. This may enhance the electrostriction of water molecules resulting in increase of $\varphi_{\mathrm{V}}{ }^{0}$ is due to enhancement in electrostriction of water molecules which will lead to decreasing of interaction in the solution ${ }^{13}$. Hence, such a decreasing values of $\varphi_{\mathrm{V}}{ }^{0}$ in aqueous alkali metal halides solution clearly indicate the strengthening of ion-solvent interaction. Also, it is interesting to note that these values are higher in System-IV, comparing the other systems indicating a strong ion-solvent interactions in this system. It is evident from the Table 3 that the values of $S_{\mathrm{V}}$ are positive in all the four liquid systems and increase with increase of temperature. Such a possession of positive values of $S_{V}$ clearly indicates the presence of strong ion-ion interactions in the solution.

The values of partial transfer volume $\left(\Delta \varphi_{V}{ }^{0}\right)$ in the present study exhibit positive deviations in all the four liquid systems and increase with elevation of temperature. The increasing behavior of partial transfer volume values $\left(\Delta \varphi_{V}{ }^{0}\right)$ shows stronger and more extensive interactions between sucrose and co-solute and vice versa. This partial transfer volume $\left(\Delta \varphi_{\mathrm{V}}{ }^{0}\right)$ can be explained on the basis of Co-Sphere Overlap Model ${ }^{14}$.

The overlap of ions of co-solute and saccharide (sucrose) comes into play because of the interaction between (i) ions of co-solutes $(\mathrm{Nacl} / \mathrm{KCl} / \mathrm{KBr} / \mathrm{KI})$ and hydrophilic, $-\mathrm{OH}$ sites of saccharides molecules and (ii) ions of co-solutes and the hydrophobic parts/groups of the saccharides molecules.

The former type of interactions contributes positively and latter type of interactions contribute negatively to $\Delta \varphi_{\mathrm{V}}{ }^{0}$ values. Therefore, it is obvious from this study, (Figure 1) the positive $\Delta \varphi_{\mathrm{V}}{ }^{0}$ values obtained for the studied saccharides (sucrose) over the entire range of composition range of co-solutes indicate the hydrophilic-ionic interactions are dominating over the hydrophobic-ionic interactions ${ }^{15}$. Also, it is noticed that this parameter found more influenced in System-IV, comparing any other systems.
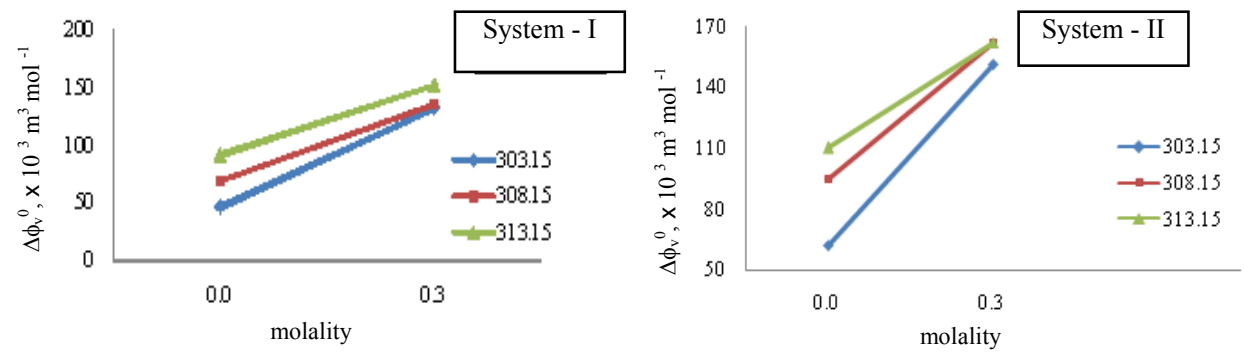

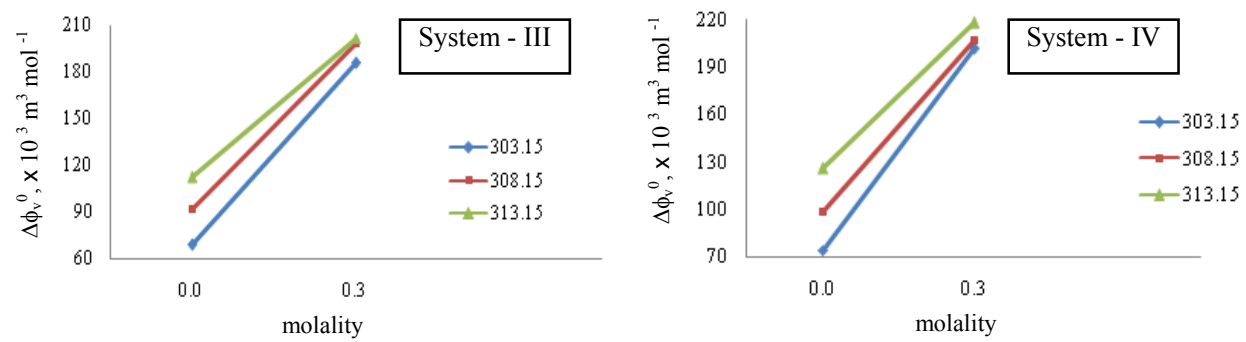

Figure 1. Variation of partial transfer volume $\left(\Delta \phi_{\mathrm{V}}{ }^{0}\right)$ with molality $(\mathrm{m})$ of sucrose in aqueous metal halides (at $0.3 \mathrm{~m}$ ) for system I,II, III \& IV at $303.15 \mathrm{~K}, 308.15$ and $313.15 \mathrm{~K}$

Viscosity is another important parameter in understanding the structure as well as molecular interactions occurring in the solutions. One can notice from Table 1, that the values of viscosity increases with increase in solute concentration in all the systems. This increasing trend indicates the existence of molecular interactions occurring in these systems. In order to shed more light on this, the role of viscosity $B$-coefficient has also been obtained. From Table 4, it is observed that the values of A are negative in all the four liquid systems studied and increase with elevation of temperature. Since A is a measure of ionic interaction and its increasing trend with elevation of temperature suggesting that ion-ion interactions get weakened. The behaviour of $B$-coefficient in all the liquid systems, where it exhibits a positive deviations suggests the existence of strong solute-solvent interaction. The present study closely observes that the elevation of temperature in the present investigation make the weakening of interionic interactions in the solution, on further addition of solute. Hence, it can be concluded that the molecular interactions between the four ternary liquid systems in the present investigation are of the order: System-IV $>$ System-III $>$ System-II $>$ System I.

\section{Conclusion}

The present investigation has been summarized as the partial transfer volume studies predict that ion-ion interactions are prevailing in the present system of mixtures thereby establishing that strong solute-co-solute interactions are existing in the present study. It also observes that a strong solute-solvent, solute-solute- ion-ion, ion-solvent, solute-co-solute etc., interactions in the present systems of liquid mixtures. However, the elevation of temperature make the interioic interactions get weakened on further addition of solute. The molecular interactions among the four liquid systems from this study are of the order: System-IV $>$ System-III $>$ System-II $>$ System-I.

\section{References}

1. Goldberg R N and Tewari Y B, J Phys Chem Ref Data, 1989, 18, 809.

2. Boerio Goates J, J Chem Themodym., 1991, 23(5), 403-409;

DOI:10.1016/S0021-9614(05)80128-4.

3. Miller D P and De Pablo J J, J Phys Chem., 2000, B104(37), 8876-8883; DOI:10.1021/jp000807d.

4. Thirumaran S and Kannappan A N, Global J Mol Sci., 2009, 4, 160-166.

5. Uedaira J P, Bull Chem Soc Jpn., 1980, 53(9), 2451-2455; DOI:10.1246/bcsj.53.2451.

6. Morel J P, Lhermet C and Dersosiers N M, Can J Chem., 1986, 64(5), 996-1001; DOI:10.1139/v86-167. 
7. Rongere P, Desrosiers N M and Morel J P, J Chem Soc Faraday Trans., 1995, 91, 2771-2777; DOI:10.1039/FT9959102771.

8. Reena Gupta and Mukhatar Singh, J Chem Sci., 2005, 117(3), 275-282; DOI:10.1007/BF02709298.

9. Thirumaran S and Inbam P, Indian J Pure Appl Phys., 2011, 49, 451-459.

10. Nithyanandam S and Palaniappan L, Chem Sci Trans., 2013, 2(1), 35-40; DOI:10.7598/cst2013.262.

11. Palani R and Geetha A, Rasay J Chem., 2008, 1(1), 46-54;

12. Thirumaran S and Job Sabu K, Indian J Pure Appl Phys., 2009, 47, 87-96.

13. Thirumaran S and Mary Christina Gardilya D, Recent Res Sci Tech., 2011, 3(8), 56-63.

14. Gurney R W, Ionic Processes in Solution, Mcgraw Hill, New York, 1953.

15. Thirumaran S and Job Sabu K, J App Sci., 2011, 11(18), 3258-3266; DOI:10.3923/jas.2011.3258.3266. 